\title{
Hot salt stress corrosion cracking by silver chloride in Ti-6Al-2Sn-4Zr-6Mo
}

\author{
Yitong Shi ${ }^{1}$; Sudha Joseph ${ }^{1}$; Trevor Lindley ${ }^{1}$; Rebecca Sandala ${ }^{2}$; Edward Saunders ${ }^{3}$; David Dye ${ }^{1}$ \\ 1 Department of Materials, Imperial College London,
}

2 Rolls-Royce plc., Materials, Elton Road, Derby DE24 8BJ, UK

3 Rolls-Royce plc., Materials-Failure Investigation, Bristol, BS 34 7QE, UK

\begin{abstract}
$\underline{\text { Abstract }}$
Hot salt stress-corrosion cracking (HSSCC) of titanium alloys has been found in the presence of chloride and other halide salts. Here, a series of $\mathrm{AgCl} \mathrm{HSSCC}$ tests on Ti-6246 were conducted using a two-point bending rig at $380-500^{\circ} \mathrm{C}$ to determine the boundary conditions of stress and temperature. Rapid failure occurred after 24 hours above $440{ }^{\circ} \mathrm{C}$, whilst the trigger stress of HSSCC was determined to be $400 \mathrm{MPa}$ at $380{ }^{\circ} \mathrm{C}$. Energy dispersive X-ray during scanning transmission electron microscopy (STEM-EDX) suggested the formation of metallic silver and chlorides of active alloying elements Al, Sn and Zr. The transgranular fracture surface is expected to be linked to an underlying hydrogen embrittlement via hydrogen charging from the corrosion reactions.
\end{abstract}

\section{Introduction}

Titanium and its alloys play a predominant among the structural materials used for aerospace applications, owing to the benefits of weight saving, excellent corrosion resistance and good mechanical properties at moderate temperature $\left(300-600^{\circ} \mathrm{C}\right)$. Ti- 6246 is an $\alpha+\beta$ alloy with high tensile strength at intermediate temperatures used in rotating components in the high pressure compressor stages of aero gas turbines. Titanium can readily form a coherent and self-healing oxide film $\left(\right.$ mainly $\left.\mathrm{TiO}_{2}\right)$ on its surface, which results in the superior corrosion resistance in most circumstances. However, the susceptibility of Ti alloys to HSSCC began to draw attention in the 1960s when a Ti-6Al-4V turbine blade failed in laboratory creep testing due to HSSCC caused by chloride salt contamination above $250{ }^{\circ} \mathrm{C}$ [1]. HSSCC associated with $\mathrm{AgCl}$ was first observed in a Ti-7Al-4Mo compressor disk at the region in intimate contact with the silver-plated bolts [2]. X-ray diffraction identified the presence of $\mathrm{AgCl}$ at the crack origin. It was believed that $\mathrm{AgCl}$ can be generated by Ag lubricant reacting with a small amount of chlorine gas $(<1 \mathrm{ppm})$ in the test environment, triggering HSSCC above $380{ }^{\circ} \mathrm{C}$ [2]. It continues to be crucial to understand these cracking mechanisms to allow the safe design and operation of gas turbine Ti components.

Recently, $\mathrm{NaCl} \mathrm{HSSCC}$ in Ti-6246 was studied at 350-450 ${ }^{\circ} \mathrm{C}$ [3-5]. Trace $\mathrm{Cl}$ was detected by EDX in the corrosion products formed on the fracture surface and in adjacent corrosion pits. It was proposed that the protective oxide layer could be broken by salt attack at high temperature, exposing the base alloy to the corrosive environment. The reactions between base alloy, salt and atmospheric moisture provide a constant supply of $\mathrm{HCl}$. Crack initiation normally occurs at the channels or pits from salt attack. Hydrogen deposited into the metal at the crack tip is suggested to result in embrittlement, assisting crack propagation either by brittle hydride formation or other mechanisms associated with solute hydrogen ahead of crack tip, e.g. hydrogen enhanced local plasticity (HELP) and adsorption induced dislocation emission (AIDE). Active alloying elements such as $\mathrm{Al}$, $\mathrm{Sn}$ and $\mathrm{Zr}$, were also found in elevated quantities on the corroded surfaces, presumably as a result of the preferential formation of alloy chlorides (which may subsequently also react to form oxides).

The $\mathrm{AgCl}$ SCC mechanism has not been recently studied in similar detail, although there is an extensive research literature on the effects of $\mathrm{NaCl}$ and other sea water containing chlorides on the SCC of different Ti alloys. The objective of the present work is to investigate the stress/ temperature boundary conditions for $\mathrm{AgCl} \mathrm{HSSCC}$ in Ti-6246, and to understand the $\mathrm{AgCl}$ reaction chemistry by study of the corrosion products by STEM-EDX.

\section{Material and experiments}

Cuboidal Ti-6Al-2Sn-4-Zr-6Mo (wt\%) samples $60 \mathrm{~mm} * 3.5 \mathrm{~mm} * 1.5 \mathrm{~mm}$ in size were obtained by electrical discharge machining (EDM), grinding and hand polishing from material provided by Rolls-Royce plc. The alloy possessed a basketweave lamellar microstructure, Figure 1(a), consisting of primary $\alpha$ laths $\left(\alpha_{\mathrm{p}}\right)$ embedded in prior $\beta$ grains with fine secondary $\alpha\left(\alpha_{\mathrm{s}}\right)$ as precipitated between the $\alpha_{\mathrm{p}}$ laths. Mechanical loads were applied using a two-point bending rig designed according to ASTM standard (E29014), as shown in Figure 1(b). The body of the bend rig was made of Ti-64 while the bolt was made of gr5 CP Ti. The maximum applied stress on the centre of the specimen was calculated using [6]:

$H=\frac{K t E(T) \sin (L \sigma / K t E(T))}{\sigma}$

where $\mathrm{H}$ represents the distance between two ends of the strip after bending to achieve the desired stress $\sigma$ on the top point, $\mathrm{L}$ and $\mathrm{t}$ correspond to length and thickness of the specimen respectively, $\mathrm{E}(\mathrm{T})$ is the Young's modulus of Ti-6246 at temperature T, and $\mathrm{K}$ is an empirical constant. The Ti-6246 strip was loaded in the rig and then a drop of $\mathrm{AgCl}$ suspension was applied to the top of the strip, consisting of $0.3 \mathrm{~g}$ of $\mathrm{AgCl}$ powder (maximum particle size $\sim 150 \mu \mathrm{m}$ ) in $100 \mathrm{ml} \mathrm{D}_{2} \mathrm{O}$. The bending rig with specimen then was 
placed into a furnace for $24 \mathrm{~h}$ at temperatures of 380,440 and $500{ }^{\circ} \mathrm{C}$. For reference, the melting point of pure $\mathrm{AgCl}\left(\mathrm{T}_{\mathrm{m}}\right)$ is $457{ }^{\circ} \mathrm{C}$. At each temperature, the specimens were tested under a range of stresses from 150 to $700 \mathrm{MPa}$ to investigate the threshold stress required to trigger HSSCC. The microstructure of the specimens after corrosion tests were characterized by optical microscopy and scanning electron microscopy (SEM) respectively. An FEI Helios Nanolab DualBeam Ga Focused Ion Beam (FIB)-FEGSEM was used to observe the microstructure underneath the corrosion products. A platinum coating was applied to protect the surface from ion milling damage. A trench was then milled in the specimen surface to expose and polish a cross-section, and then a TEM foil was obtained by conventional FIB milling. STEM- EDX was then undertaken in a JEOL 2100F FEGTEM at an accelerating voltage of $200 \mathrm{kV}$.

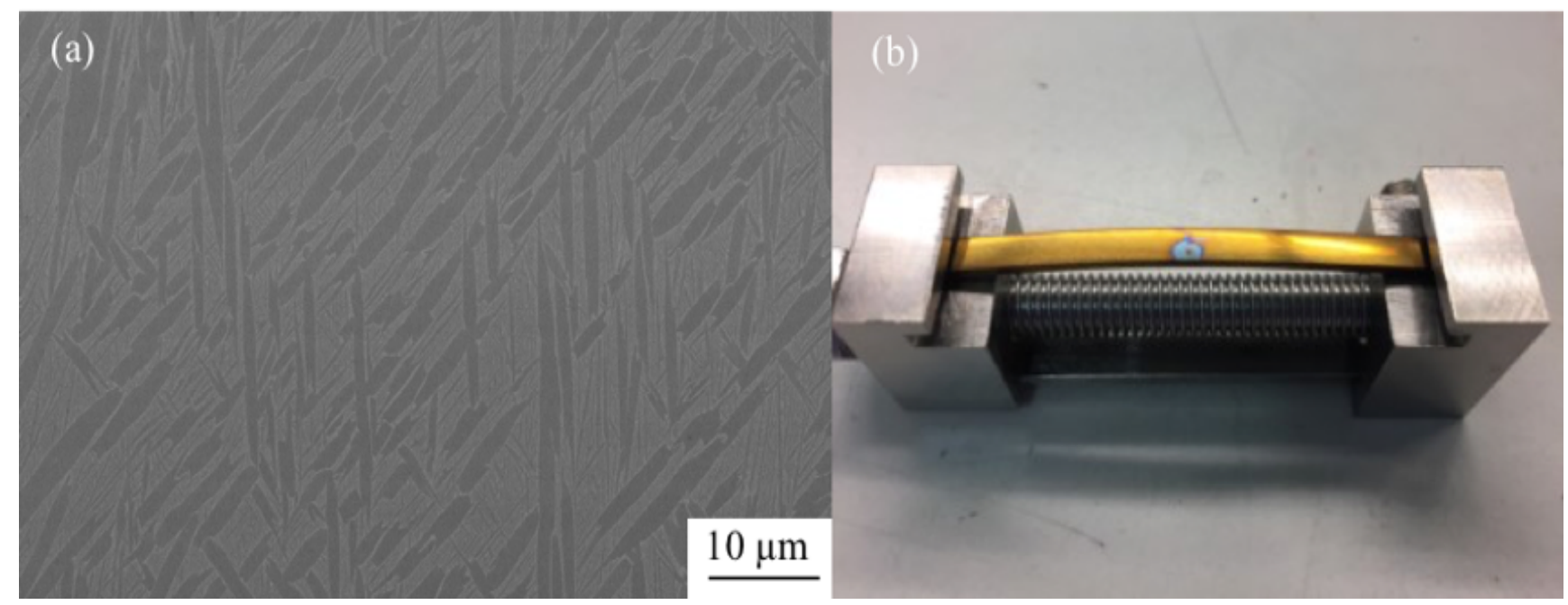

Figure 1. (a) Backscattered electron SEM image of as-received Ti-6246 showing the $\alpha+\beta$ basketweave microstructure; (b) two-point bending rig containing a corroded and cracked Ti-6246 specimen.

\section{$\underline{\text { Results }}$}

Table 1 summarizes the results of the $24 \mathrm{~h}$ bending tests. Rapid failures occurred at $500^{\circ} \mathrm{C}$ at all stresses examined; a side view of a failed sample is shown in Figure 2(a). A thick layer of corrosion product was generated near the crack., with a blue colouration around the corroded area due to the formation of oxide. At $440{ }^{\circ} \mathrm{C}$ (below $\mathrm{T}_{\mathrm{m}}$ of $\mathrm{AgCl}$ ), macroscopic sample failure was not observed at $400 \mathrm{MPa}$ and below, but significant cracking was still observed. The fracture surface exhibited a transgranular appearance with the deposition of corrosion products, as shown in Figure 2(b). At $380{ }^{\circ} \mathrm{C}$, cracking was absent for stresses of 400 $\mathrm{MPa}$ and below, whilst cracking was observed at $500+\mathrm{MPa}$. Therefore $400 \mathrm{MPa}$ can be considered to be the stress boundary condition for triggering HSSCC within $24 \mathrm{~h}$. Figure 2(c) showed that a small crack initiated beneath the salt particles on the top surface of the $380{ }^{\circ} \mathrm{C} / 500 \mathrm{MPa}$ specimen. The optical image also shows the underlying microstructure, a result of preferential oxidation and corrosion of the primary $\alpha$ laths compared to the transformed $\beta$; such rapid preferential oxidation is not usually observed for these heat treatment conditions in the absence of corrodant. The secondary electron image in Figure 2(d) shows the same crack at a higher magnification; it can be observed that the crack propagated across $\alpha_{p}$ laths, with the formation of nodular corrosion products.

Table 1. Results of isothermal 24 h hot salt stress corrosion 2-point bend tests in Ti-6246.

\begin{tabular}{c|ccc} 
Stress $(\mathrm{MPa})$ & $380^{\circ} \mathrm{C}$ & $440^{\circ} \mathrm{C}$ & $500^{\circ} \mathrm{C}$ \\
\hline 150 & No cracking & Cracking & Failed \\
200 & No cracking & Cracking & Failed \\
300 & No cracking & Cracking & Failed \\
400 & No cracking & Cracking & Failed \\
500 & Cracking & Failed & Failed \\
600 & Cracking & Failed & Failed \\
700 & Cracking & Failed & Failed
\end{tabular}



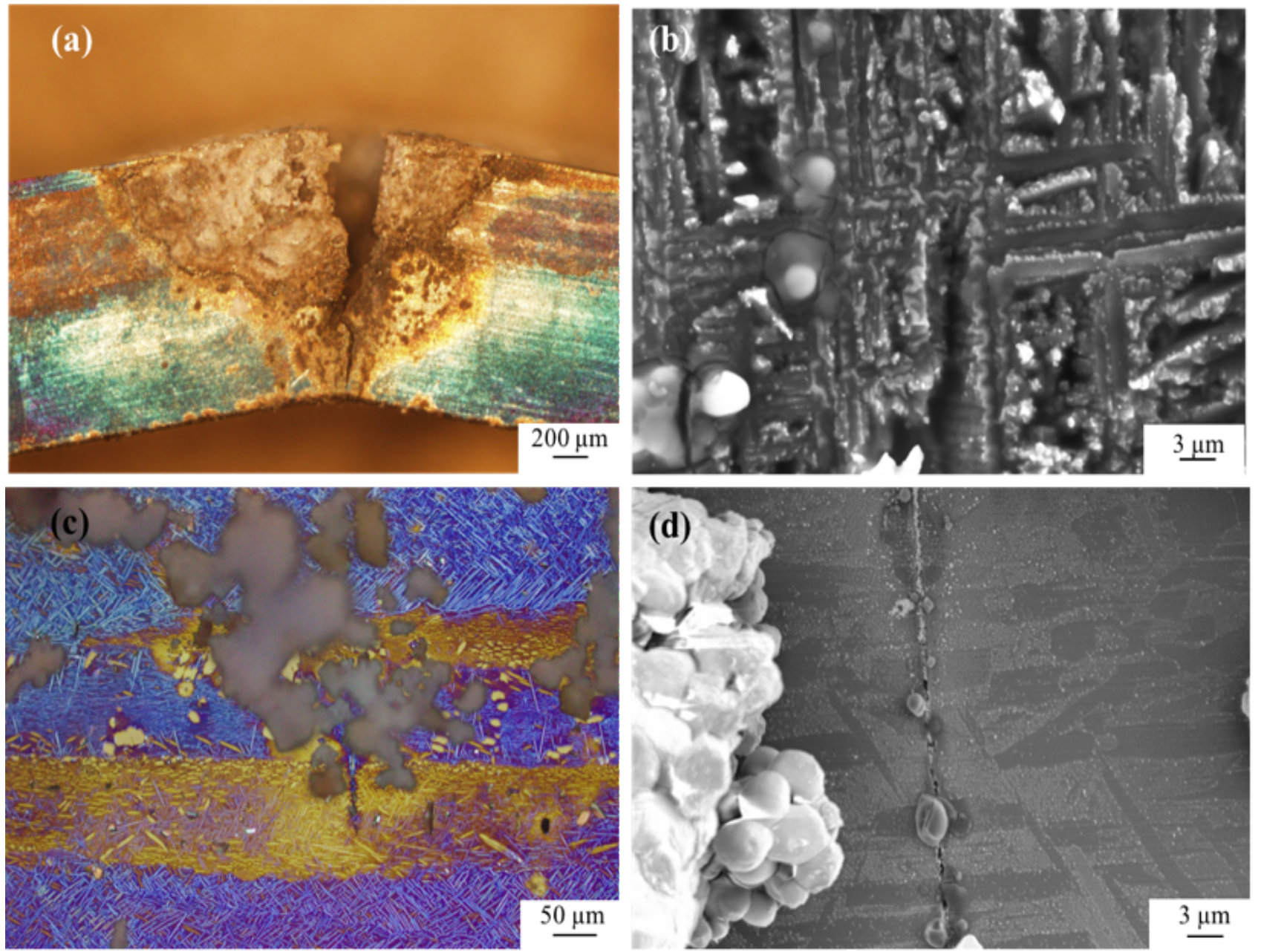

Figure 2. (a) Optical image of the side view showing failure of the specimen after testing at $500{ }^{\circ} \mathrm{C} / 700 \mathrm{MPa}$; (b) SE image showing the fracture surface covered by corrosion products after the $440{ }^{\circ} \mathrm{C} / 600 \mathrm{MPa}$ test; (c) optical image and (d) SE image revealing a small crack formed on the top surface of the specimen tested at $380{ }^{\circ} \mathrm{C} / 500 \mathrm{MPa}$.

Wavy, snake-like structures were extensively observed on the top surfaces of the specimens, Figure 3(a). To investigate these, FIB milling was utilized to make a trench to expose the cross section of a snake-like structure. Figure 3(b) and (c) show that it formed on a primary $\alpha$ lath and that the inside was hollow with some particles precipitated in the interior. These particles nearly pure Ag $(>93$ at\%), deduced to be metallic Ag. The outer shell was about $200 \mathrm{~nm}$ in thickness and was close in composition to titanium dioxide. Some deposits containing Ti, Al and $\mathrm{O}$ were formed inside the walls of this structure. The underlying alloy was found to be oxygenenriched near the surface of the $\alpha$ lath, and the locally Al-enriched layers were formed above base alloy and Ag-rich region, indicating the upwards diffusion of Al.

A similar TEM lamella obtained from a crack was examined by STEM-EDX, Figure 4. Some platinum deposit from the preparation process can be observed within the open crack mouth. A small Ag and Sn precipitate is observed in the crack, with the crack faces consisting of a layer enriched in $\mathrm{O}$ (up to $45 \mathrm{at} \%$ ) and $\mathrm{Cl}$ (several at\%). In this region, the Al/Ti ratio was also elevated compared to the base alloy, indicating the outward diffusion of $\mathrm{Al}$, which is suspected to be a preferential former of volatile metal chloride. 


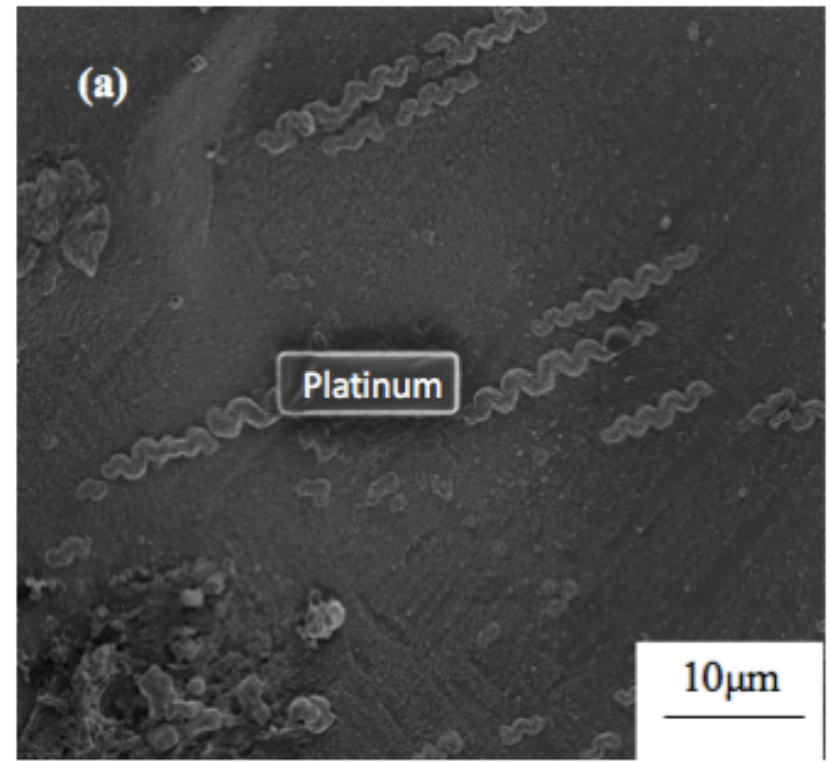

(b)

\section{Platinum}
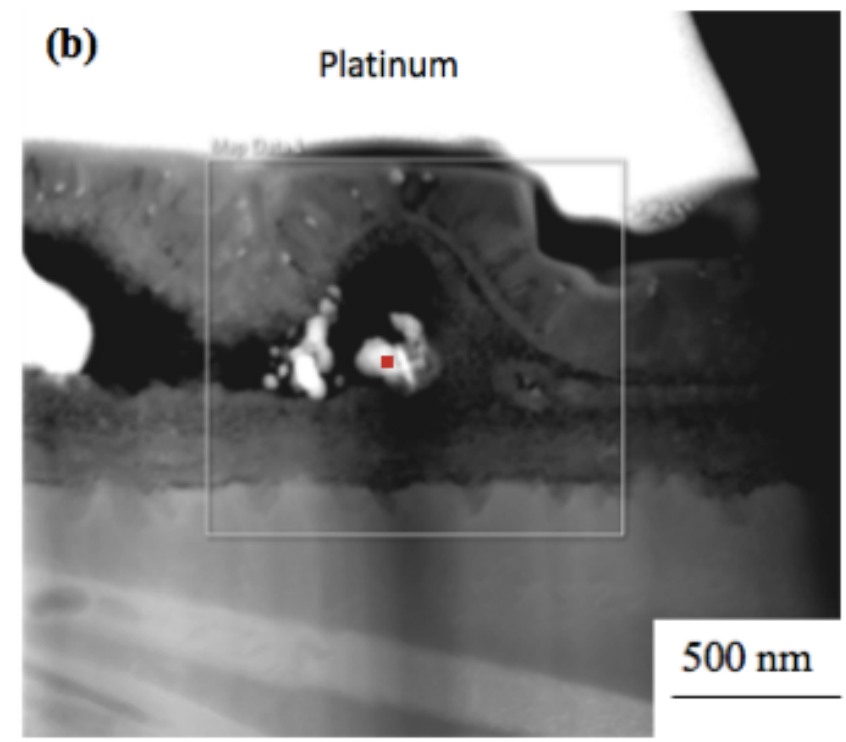

$500 \mathrm{~nm}$

(c)
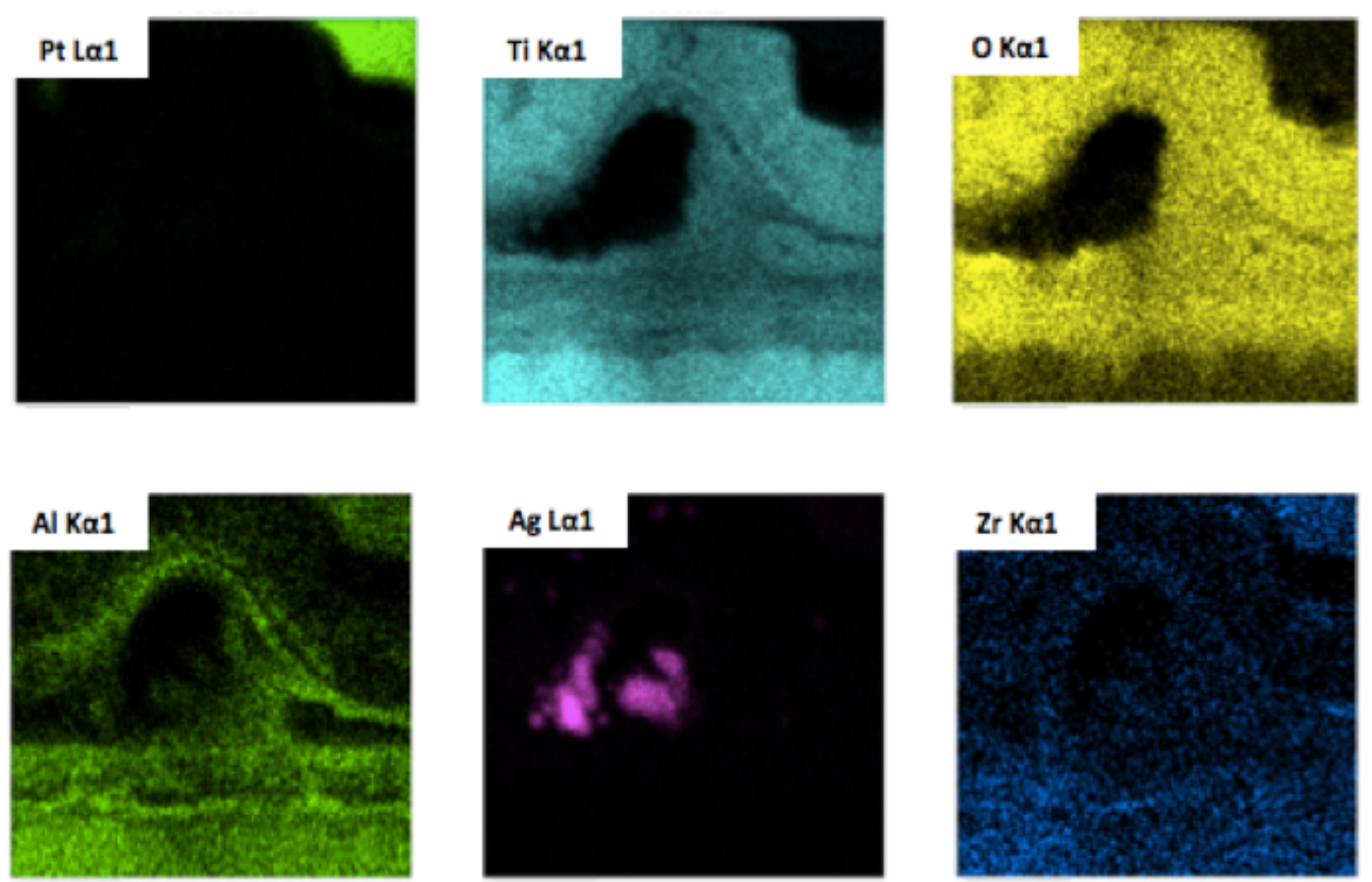

$250 \mathrm{~nm}$

Figure 3. (a) Focused-ion beam (FIB) image showing a snake-like structure formed on the top surface and protected by platinum deposition, taken under the voltage of $30 \mathrm{kV}$ and current of $27 \mathrm{pA}$; (b) STEM dark field image on the cross-section of the snake-like structure; (c) STEM-EDX map of the cross section showing the structure of the layers formed. 

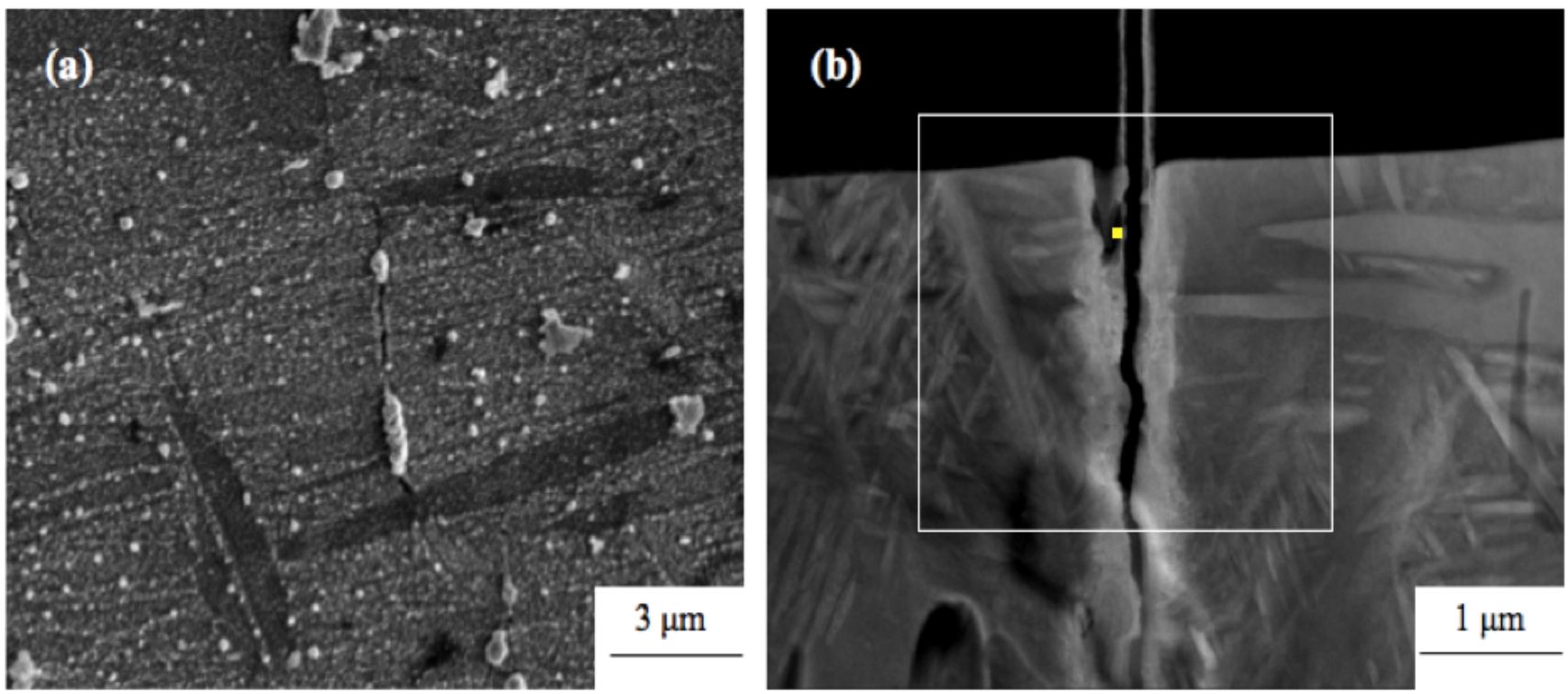

(c)
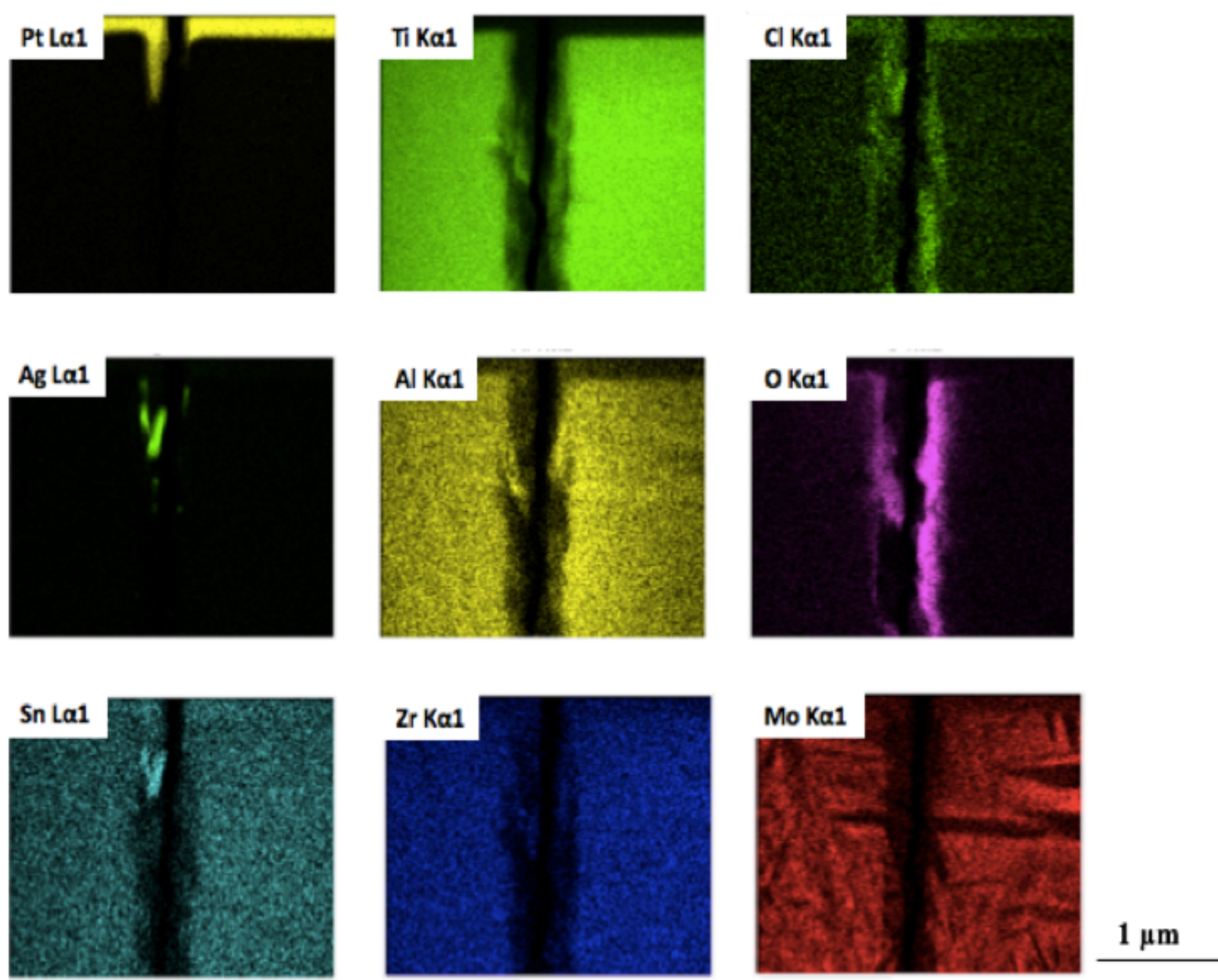

Figure 4. STEM bright field image (b) taken from the platinum coated region (a) containing a crack propagating from top surface down to the base alloy (the white rectangular box indicating the area analysed by STEM-EDX under camera length $20 \mathrm{~cm}$, spot size $1.5 \mathrm{~nm}$ ); (c) STEM-EDX mapping showing the distributions for different elements

Table 2. STEM-EDX spot analyses from locations indicated in Figures 3(b) (red) and 4(b) (yellow). 


\begin{tabular}{c|ccccccccc} 
Red dot & $\mathrm{Ag}$ & $\mathrm{Ti}$ & $\mathrm{O}$ & $\mathrm{Cl}$ & $\mathrm{Al}$ & $\mathrm{Sn}$ & $\mathrm{Zr}$ & $\mathrm{Mo}$ & $\mathrm{Pt}$ \\
\hline wt\% & 95.2 & 0.21 & 0.02 & 0 & 0.3 & 0 & 0.1 & 4.1 & 0 \\
at\% & 93.5 & 0.47 & 0.13 & 0 & 1.2 & 0 & 0.12 & 4.5 & 0 \\
\hline Yellow dot & & & & & & & & & \\
wt\% & 69.7 & 10.7 & 1.5 & 0 & 0.5 & 1.4 & 0.4 & 1 & 14.9 \\
at\% & 59.8 & 20.6 & 8.4 & 0 & 1.6 & 1.1 & 0.4 & 1 & 7.1
\end{tabular}

\section{$\underline{\text { Discussion }}$}

A series of isothermal bending tests were performed on Ti-6246 to evaluate the susceptibility of HSSCC in the presence of AgCl. At $500^{\circ} \mathrm{C}$, failures happened even under low stress within $24 \mathrm{~h}$. Since the temperature was higher than the $\mathrm{T}_{\mathrm{m}}$ of $\mathrm{AgCl}\left(457^{\circ} \mathrm{C}\right)$, the molten salt could provide an aggressive environment, leading to rapid failure. When temperature was lowered below $\mathrm{T}_{\mathrm{m}}, \mathrm{AgCl}$ salt particles were found randomly distributed on the surface after evaporating moisture from the suspension. Crack initiation usually took place underneath an isolated salt particle. It was speculated that this process was assisted by the attack of the protective oxide film by $\mathrm{AgCl}$. The requirement is for the threshold stress and local chemistry conditions to achieve a film rupture rate greater than the repassivation rate. Apparently, the crack propagation rates decreased with decreasing temperature. Elevated temperatures can boost the rates for surface reaction, diffusion and adsorption. Mass transport of corrosive species along the crack tip can also be accelerated, which is considered as the rate-controlling step for most circumstances [2]. In addition, the reaction chemistry and therefore cracking mechanisms may also be temperature dependent. Therefore, $\mathrm{K}_{\mathrm{ISCC}}$ can be expected to have a dependence on temperature. In this work, the reaction chemistry below $\mathrm{T}_{\mathrm{m}}$ is the primary object of study.

EDX analysis on the snake-like structures suggested the occurrence of strong oxidation on certain preferred primary $\alpha$ laths. Metallic $\mathrm{Ag}$ could be formed though the cathodic reaction, assuming silver ions freely diffuse from the salt coated region through the interface between oxide and base alloy. Besides, it has been found that $\mathrm{Al}$ and $\mathrm{Zr}$ are very active and able to diffuse upward to react, which conforms to the findings from previous studies [3,4]. The hollow structure might result from the expansion of Ag particles or formation of gaseous chlorides on the Ag particles. It has been reported that titanium and aluminium chlorides have relatively low boiling points and are volatile at temperatures above $200{ }^{\circ} \mathrm{C}$ [7]. Simultaneously, oxidation was greatly enhanced, stimulated by the local electrochemical reactions around the silver particles. The reasons for the wavy shapes of those structures and their formation on preferred $\alpha$ laths can be speculated to be a consequence of the orientation and defect structures of the underlying primary $\alpha$ laths. There is no any evidence to link these structures to crack initiation sites; the snake-like features were associated with the formation of a thicker oxide shell (about $250 \mu \mathrm{m}$ ) than in other areas.

Figure 4 showed a TEM lamella containing a crack. Pitting was not observed in this crack initiation region, but a layer of precipitation rich in $\mathrm{Ag}$ (about 60 at\%) was generated near the crack mouth and penetrated down. This layer also consisted of Ti, $\mathrm{O}, \mathrm{Al}$ and $\mathrm{Sn}$, so there could be multiple compounds formed after degradation of the original oxide film. Both $\mathrm{Al}$ and $\mathrm{Sn}$, which are easier chloride formers than $\mathrm{Ti}$ and segregate to the $\alpha$ phase, participated in the reactions. It has been reported in literature [8] that the equilibrium solid solubility of $\mathrm{Sn}$ in $\mathrm{Ag}$ is beyond 11 at\%, which suggests that Sn could form a low melting point Ag-Sn eutectic in this case. There were some thin ligaments present below this precipitate layer consisting of the oxides of $\mathrm{Ti}, \mathrm{Al}$ and $\mathrm{Zr}$. It should be noted that trace chlorine penetrated down through the crack while Ag was only found at the crack month. The diffusion of chlorine along crack walls is expected to be a consequence of vapour transport (e.g. in $\mathrm{HCl}$ ) at elevated temperatures. It has been postulated in previous work [9] that the gaseous $\mathrm{Cl}_{2}$ and $\mathrm{HCl}$ are likely to be released as a byproduct from reactions with moisture and attack the alloy. Also, various gaseous alloy chlorides (e.g. $\mathrm{TiCl}_{4}, \mathrm{AlCl}_{3}$ ) can be produced under this temperature range. The transgranular fracture appearance can be also linked to hydrogen embrittlement. Hence, it is expected that hydrogen embrittlement in associated with the mechanism of cracking, but the nature of the crack tip hydrogen should be explored in the future work.

\section{Conclusions}

Isothermal bend tests were performed on Ti-6246 were performed to evaluate its susceptibility to hot salt stress corrosion cracking by $\mathrm{AgCl}$, and the chemical compositions of corrosion products were examined by STEM-EDX. The following conclusions are drawn:

1. In this condition, the material examined can sustain $\mathrm{AgCl}$-associated hot salt stress corrosion attack for $24 \mathrm{~h}$ at stresses and temperatures below $400 \mathrm{MPa}$ and $380^{\circ} \mathrm{C}$;

2. Primary $\alpha$ laths are preferentially be attacked, forming thick oxides. Al and $\mathrm{Sn}$ diffuse out from the base alloy to react with the salt;

3. Hydrogen embrittlement is suggested to be responsible for HSSCC, as inferred from the transgranular fracture appearance.

\section{Acknowledgements}

The authors would like to thank Rolls Royce plc. for provision of materials and for co-funding this project. 


\section{$\underline{\text { References }}$}

1. Jones, Russell H., ed. Stress-Corrosion Cracking, Materials performance and evaluation. ASM international, 2017.

2. Duttweiler, R., R. Wagner, and K. Antony. "An investigation of stress-corrosion failures in titanium compressor components." Stress-Corrosion Cracking of Titanium. ASTM International, 1966.

3. Joseph, Sudha, et al. "The mechanisms of hot salt stress corrosion cracking in titanium alloy Ti-6Al-2Sn-4Zr6Mo." Corrosion Science 134 (2018): 169-178.

4. Chapman, T. P., et al. "Environmentally assisted fatigue crack nucleation in Ti-6Al-2Sn-4Zr-6Mo." Corrosion Science 96 (2015): 87-101.

5. Cao, Sheng, et al. "The mechanism of aqueous stress-corrosion cracking of $\alpha+\beta$ titanium alloys." Corrosion Science125 (2017): 29-39.

6. Haaijer, G., and A. W. Loginow. "Stress analysis of bent-beam stress corrosion Specimens." Corrosion 21.4 (1965): $105-112$.

7. Ondrejcin, R. S. "Chlorine gas and fluoride ion in hot-salt stress corrosion cracking of titanium-aluminum alloys." (1969).

8. Yuantao, Ning, and Zhou Xinming. "Metastable extension of solid solubility of alloying elements in silver." Journal of alloys and compounds 182.1 (1992): 131-144.

9. Ciszak, Clément, et al. "NaCl induced corrosion of Ti-6Al-4V alloy at high temperature." Corrosion Science 110 (2016): $91-$ 104. 